\title{
Preconception Care among Pregnant Women in an Urban and a Rural Health Facility in Kenya: A Quantitative Study
}

\author{
Joan Okemo ${ }^{1, *}$, Marleen Temmerman ${ }^{1}\left(\mathbb{D}\right.$, Mukaindo Mwaniki ${ }^{1}\left(\mathbb{D}\right.$ and Dorothy Kamya ${ }^{2}$ \\ 1 Department of Obstetrics ad Gynecology, Aga Khan University Hospital, Nairobi 30270-00100, Kenya; \\ marleen.temmerman@aku.edu (M.T.); mukaindo.mwaniki@aku.edu (M.M.) \\ 2 Department of Postgraduate Medical Education, Aga Khan University Hospital, Nairobi 30270-00100, Kenya; \\ dorothy.kamya@aku.edu \\ * Correspondence: joan.okemo@aku.edu; Tel.: +254-727-360-065
}

Received: 21 July 2020; Accepted: 23 September 2020; Published: 13 October 2020

\begin{abstract}
Preconception care (PCC) aims to improve maternal and fetal health outcomes, however, its utilization remains low in developing countries. This pilot study assesses the level and determinants of PCC in an urban and a rural health facility in Kenya. Unselected pregnant women were recruited consecutively at the Mother and Child Health $(\mathrm{MCH})$ clinics in Aga Khan University Hospital, Nairobi (AKUH, N-urban) and Maragua Level Four Hospital (MLFH-rural). The utilization of PCC was defined as contact with any health care provider before current pregnancy and addressing pregnancy planning and preparation. A cross-sectional approach was employed and data were analyzed using SPSS version 22. 194 participants were recruited (97 in each setting) of whom, $25.8 \%$ received PCC. Age, marital status, education, parity and occupation were significant determinants of PCC uptake. There was also a significant difference in PCC uptake between the rural $(16.5 \%)$ and urban $(35.1 \%)$ participants $(p<0.01)$, OR of $0.3(0.19-0.72,95 \%$ CI). The low level of PCC in Kenya revealed in this study is consistent with the low levels globally. However, this study was not powered to allow firm conclusions and analyze the true effects of PCC determinants. Therefore, further research in the field is recommended in order to inform strategies for increasing PCC utilization and awareness in Kenya.
\end{abstract}

Keywords: preconception care; Kenya; urban; rural; level; determinants; utilization

\section{Introduction}

The World Health Organization (WHO) defines preconception care (PCC) as the provision of biomedical, behavioral and social health interventions to women and couples before conception occurs, with the aim of improving their health status, and mitigating behaviors, individual and environmental factors that could contribute to poor maternal and child health outcomes [1,2]. This is done through risk identification, health education and promotion and initiation of evidence-based interventions in the period prior to conception. The use of PCC use in high- and in low-income countries aims to improve maternal pregnancy and neonatal outcomes both in the short and long term [3].

The Ministry of Health in Kenya recommends PCC as one of the pillars aimed at attaining the fourth and fifth Millennium Development Goals (MDGs) that aim to reduce child mortality and improve maternal health respectively [4]. These MDGs were followed by the Sustainable Development Goals (SDGs), where SDG 3 aims to ensure healthy lives and promote well-being for all at all ages by 2030 [5]. The Kenya National Reproductive Health System (KNRHS) of 2009-2015 [4] recognizes PCC and family planning as one of the pillars of maternal and newborn health. Others include focused antenatal care (ANC), essential obstetric care, essential newborn care, targeted postpartum care and 
post-abortion care. These were deemed essential in accomplishing MDGs four and five [6]. While the other pillars had laid out strategies for implementation, there is a paucity of data with regard to how PCC was to be implemented nationwide.

Several studies conducted to look at the level of PCC in other parts of the world found the levels to be generally low. A study conducted by Frey and Files in Mayo clinic [7] found that only 39\% of the women received PCC from their primary care physicians compared to $98.6 \%$ who believed in its importance. Ezegwui et al. [8] in Southeastern Nigeria found that $43.1 \%$ of their study participants were aware of PCC and of these, $64.4 \%$ had correct knowledge. Only $32.6 \%$ of the aware group (14\% overall) involved a health practitioner during the planning of their pregnancies despite a good percentage having a planned pregnancy (68.4\%). Stephenson et al. [9] found that $27 \%$ of the women in their study sought advice from health providers about getting pregnant despite a $73 \%$ rate of planned pregnancies.

Some studies in Africa have demonstrated a difference in the level of PCC among women in urban and rural settings. Ezegwui et al. [8] and Ekem et al. [10] in Southeastern Nigeria conducted their studies in urban settings and found the level of PCC awareness to be $43.1 \%$ and $44.2 \%$, with a $14 \%$ and $10.3 \%$ rates of utilization respectively. A different study by Idris et al. [11] in Northwestern Nigeria in a semi-urban setting found only $4 \%$ of the 150 recruited women were aware of PCC and the level of utilization was $2.7 \%$.

While there were no studies identified in the literature that looked at the level and determinants of PCC in Kenya, the statistical differences in the level of other forms of maternal health services in urban and rural Kenya may imply differences in PCC as well. In Kenya, $4 \%$ of pregnant women do not seek ANC at all (5.3\% in rural versus 1.8\% in urban) [12]. According to KDHS 2014 [12], contraceptive prevalence rate (CPR) was $62 \%$ in urban and $56 \%$ in rural areas. Efforts to increase CPR in Kenya have been met by challenges such as poverty, religious, cultural beliefs and practices and weak health systems [4]. Other statistical differences were: level of unmet contraceptive need of $13 \%$ (urban) and 20\% (rural); women who received ANC from a skilled health provider were $97.8 \%$ (urban) and $94.0 \%$ (rural) and women who sought postnatal care were $65 \%$ (urban) and $42.7 \%$ (rural).

Our study aimed to compare the level of PCC utilization and its determinants among pregnant women in urban (Aga Khan University Hospital, Nairobi-AKUH, N) and rural (Maragua Level Four Hospital-MLFH) settings in Kenya.

\section{Materials and Methods}

The study's definition of PCC utilization was contact with any health provider before current pregnancy and having discussed pregnancy planning and preparation. To elicit the level of PCC utilization, we used question 3 in section four of the questionnaire which stated, "I talked about pregnancy plans and preparation with a health care provider before I got pregnant".

An analytic cross-sectional study was used to compare the level of PCC in AKUH, N and MLFH and some of the factors affecting PCC through a self-administered questionnaire. The study was conducted at the AKUH, N and MLFH Mother-Child Health Clinics (MCH).

$\mathrm{AKUH}, \mathrm{N}$ is an urban private, tertiary, teaching and referral health facility located in Nairobi County-an all urban county [13]. It is an academic health care centre providing tertiary level healthcare. Aga Khan Hospital was founded in 1955 and became part of the Aga Khan University in 2005 which evolved it into a premier teaching and tertiary care referral hospital. AKUH, $\mathrm{N}$ has a bed capacity of 254 and offers state of the art services including maternity and antenatal services in the MCH clinic. From the AKUH, N maternity records, about 800 women are seen in the $\mathrm{MCH}$ clinic monthly and on average, 350 deliveries are conducted monthly in the maternity ward with approximately $45 \%$ of these being caesarian deliveries.

MLFH is a public hospital located about one kilometer from Maragua town in the southern part of Murang'a County [14]. Level four hospitals are the first referral hospitals in Kenya, with both outpatient and inpatient health services and referral services. They have the following clinical services which are run by either an on-site specialist in the field or a specialist who covers several of the level 
four hospitals within the region: obstetrics and gynaecology; child health; medicine; surgery and anaesthesia. Murang'a County has a dense rural settlement with $89 \%$ of the population living in rural areas and only $11 \%$ living in urban centres. Maragua's constituency is largely rural. Most of the road linkages within the county are all-weather roads with some of the economic activities including farming, quarrying, forestry and tourism [14]. MLFH was founded in 1972 as a rural health training and demonstration centre for Kenya Medical Training College by then Minister James Njiru. It became a level four hospital for Murang'a South in 1997. It offers several services including antenatal services through the $\mathrm{MCH}$ clinic that serves over 400 pregnant women monthly. It has a bed capacity of 82 and conducts about 350 deliveries monthly with a $30 \%$ caesarian section rate.

The study population included all pregnant women attending antenatal care in one of the two hospitals. The participants were eligible if they were aged $\geq 18$ years and were able to speak English or Kiswahili. The KDHS 2014 report [12] indicates that over 97\% of pregnant women in the two counties have at least one contact with a skilled health provider. Obtaining study subjects from the population of pregnant women attending ANC in both hospitals provided a good representation of the pregnant women population and by extension, reproductive-aged women.

Due to a lack of locally published prevalence studies on PCC, we based our sample size calculation on Nigerian data using a difference in PCC prevalence of $14 \%$ in urban and $2.7 \%$ in semi-urban by Ezegwui et al. and Idris et al. respectively $[8,11]$. We calculated the sample size needed to do the study with a power of $80 \%$ and a confidence interval of $95 \%$ as 97 women in each site. The formula for difference in two proportions shown below was used for sample size calculation,

$$
n=2 \times(\mathrm{Z} \alpha+\mathrm{Z} \beta)^{2} \times \frac{\mathrm{P} 1(1-\mathrm{P} 1)+\mathrm{P} 2(1-\mathrm{P} 2)}{(\mathrm{P} 1-\mathrm{P} 2)^{2}}
$$

where,

$n=$ sample size in each group (equal sample size in each group).

$\mathrm{P} 1$ = estimated proportion of study outcome in the AKUH, $\mathrm{N}$ group (urban). In this case, $-14 \%$ as derived from the Nigerian study by Ezegwui et al. [8].

P2 = estimated proportion of the study outcome in the Maragua group (rural). In this case, $2.7 \%$ as derived from the Nigerian study by Idris et al. [11].

$\mathrm{Z} \alpha=$ critical value at the level of statistical significance (1.96)

$\mathrm{Z} \beta=$ critical value at the level of the desired power ( 0.84 for $80 \%$ power $)$.

The data collection tools were in both English and Kiswahili languages. The tools were developed based on the study objectives and literature review. They were thereafter validated on 8 antenatal women in AKUH, N and MLFH MCH clinics to test the idioms of the languages used, response time, check whether the questions were appropriately framed, inoffensive, clear, easy to understand, able to elicit discussions and address the intended questions for the study. They were found to be suitable for the study and did not require any adjustments.

Data collection was conducted during the waiting period before consultation with the health providers at the respective $\mathrm{MCH}$ clinics. A 5-10 min self-administered questionnaire was used to collect data, including the socio-demographic section (age, marital status, education, occupation, residential area); obstetric history (parity, gestational age in weeks by last menstrual period (LMP) or first-trimester scan and prior obstetrics outcomes); pre-existing medical conditions and a section with questions to determine the level of PCC prior to current pregnancy and some more determinants.

Participants were selected through consecutive sampling. All eligible participants who met the inclusion criteria were approached and explained the purpose of the study by the principal investigator and two research assistants. A hundred women were approached in $\mathrm{AKUH}, \mathrm{N}$ of whom 97 consented to participate in the study and 3 declined. A hundred and one women were approached in MLFH, of whom 97 consented to participate in the study and 4 declined. The willing participants chose their preferred language (English or Kiswahili) and were then required to sign an informed consent form. Thereafter, a 5-10 min self-administered questionnaire was given for the collection of data on socio-demographics, 
obstetrics and clinical history, level and some determinants of PCC utilization. The questionnaires were confirmed to be completely filled by the research assistants/principal investigator before a participant left. The same processes of data collection were carried out in AKUH, N and MLFH.

Data were analyzed using SPSS version 22. Descriptive analysis was done to describe the characteristics of the study participants. Binary variables were constructed to conduct further univariate analysis. The Chi-square test and Student's $t$-test were used to test for the association for the categorical and continuous variables respectively. A $p$-value of $<0.05$ was considered significant. Unadjusted odds ratios were calculated and presented with $95 \%$ confidence intervals. Variables whose $p$-values were found to be significant from the univariate analysis were subjected to further multivariate analysis through the calculation of adjusted odds ratios in order to remove the effects of potential confounders. However, because of the small study sample size, firm conclusions could not be drawn from this analysis.

All subjects gave their informed consent for inclusion before they participated in the study. The study was conducted in accordance with the Declaration of Helsinki, and the protocol was approved by the Aga Khan University Hospital Nairobi Research and Ethics Committee. The corresponding ethical approval code is Ref: 2016/REF-61(v2) dated 16 February 2017.

\section{Results}

\subsection{Study Participants}

Table 1 summarizes the characteristics of the study participants. The two groups were comparable for parity, prior pregnancy outcomes, caesarian section deliveries, medical conditions during prior pregnancy and preexisting medical conditions. However, there were significant differences in age, marital status, educational level and occupation $(p<0.05)$.

Table 1. Characteristics of study participants by site.

\begin{tabular}{|c|c|c|c|}
\hline & $\begin{array}{c}\text { AKUH, N } \\
n(\%) \text { or Mean } \pm \text { S.D }\end{array}$ & $\begin{array}{c}\text { Maragua } \\
n(\%) \text { or Mean } \pm \text { S.D }\end{array}$ & $\begin{array}{c}p \text {-Value } \\
\text { (Chi-Square/t-Test) }\end{array}$ \\
\hline \multicolumn{4}{|l|}{ Age: } \\
\hline Mean & $30.1 \pm 4.0$ & $26.8 \pm 5.4$ & \multirow[b]{3}{*}{$<0.01$} \\
\hline$<30$ years & $42(43.3)$ & $68(70.1)$ & \\
\hline$\geq 30$ years & $55(56.7)$ & $29(29.9)$ & \\
\hline \multicolumn{4}{|l|}{ Marital status: } \\
\hline Married & $84(86.6)$ & $60(61.9)$ & \multirow{4}{*}{0.01} \\
\hline Single & $12(12.4)$ & $31(32.0)$ & \\
\hline Divorced & $0(0.0)$ & $1(1.0)$ & \\
\hline Widowed & $1(1.0)$ & $5(5.2)$ & \\
\hline \multicolumn{4}{|l|}{ Education: } \\
\hline Primary & $0(0.0)$ & $18(18.6)$ & \multirow{4}{*}{$<0.01$} \\
\hline Secondary & $3(3.1)$ & $54(55.7)$ & \\
\hline Tertiary & $94(96.9)$ & $24(24.7)$ & \\
\hline None & $0(0.0)$ & $1(1.0)$ & \\
\hline \multicolumn{4}{|l|}{ Occupation: } \\
\hline Student & $5(5.2)$ & $3(3.1)$ & \multirow{5}{*}{$<0.01$} \\
\hline Unemployed & $8(8.2)$ & $21(21.6)$ & \\
\hline Farmer & $0(0.0)$ & $21(21.6)$ & \\
\hline Business & 17(17.5) & $33(34.0)$ & \\
\hline Professional & $67(69.1)$ & 19 (19.6) & \\
\hline \multicolumn{4}{|l|}{ Parity: } \\
\hline Primigravida & $33(34.0)$ & $38(39.2)$ & \multirow{2}{*}{0.46} \\
\hline Multigravida & $64(66.0)$ & $59(60.8)$ & \\
\hline
\end{tabular}


Table 1. Cont.

\begin{tabular}{|c|c|c|c|}
\hline & $\begin{array}{c}\text { AKUH, N } \\
n(\%) \text { or Mean } \pm \text { S.D }\end{array}$ & $\begin{array}{c}\text { Maragua } \\
n(\%) \text { or Mean } \pm \text { S.D }\end{array}$ & $\begin{array}{c}p \text {-Value } \\
\text { (Chi-Square/t-Test) }\end{array}$ \\
\hline Prior poor pregnancy outcomes: & $(n=64)$ & $(n=59)$ & \multirow{9}{*}{0.19} \\
\hline Yes & $43(67.2)$ & $34(57.6)$ & \\
\hline No & $21(32.8)$ & $25(42.4)$ & \\
\hline Miscarriages & $21(32.8)$ & $17(28.8)$ & \\
\hline Molar pregnancy & $1(1.6)$ & $0(0.0)$ & \\
\hline Ectopic pregnancy & $1(1.6)$ & $6(10.2)$ & \\
\hline Preterm birth & $5(7.8)$ & $3(5.1)$ & \\
\hline Stillbirth & $2(3.1)$ & $4(6.8)$ & \\
\hline Birth defects & $0(0.0)$ & $2(3.4)$ & \\
\hline Caesarian section delivery & $\begin{array}{l}(n=64) \\
16(25.0)\end{array}$ & $\begin{array}{l}(n=59) \\
17(28.8)\end{array}$ & 0.28 \\
\hline $\begin{array}{l}\text { Medical conditions during prior } \\
\text { pregnancy (such as diabetes, }\end{array}$ & $(n=64)$ & $(n=59)$ & \multirow[b]{2}{*}{0.95} \\
\hline $\begin{array}{c}\text { hypertension, cholestasis in } \\
\text { pregnancy etc.) }\end{array}$ & $4(6.3)$ & $8(13.6)$ & \\
\hline \multicolumn{4}{|l|}{ Preexisting medical conditions } \\
\hline Diabetes & $1(1.0)$ & $3(3.1)$ & \multirow{7}{*}{0.23} \\
\hline High blood pressure & $2(2.1)$ & $1(1.0)$ & \\
\hline Heart disease & $0(0.0)$ & $0(0.0)$ & \\
\hline Asthma & $4(4.1)$ & $5(5.2)$ & \\
\hline Epilepsy & $1(1.0)$ & $1(1.0)$ & \\
\hline HIV & $4(4.1)$ & $8(8.2)$ & \\
\hline None & $85(87.6)$ & $79(81.4)$ & \\
\hline
\end{tabular}

Table 2 summarizes the health-seeking behaviour of study participants by site and level of significance. There were differences in visits to health professionals, challenges of access to health care, pregnancy timing, beliefs in ability to prepare for pregnancy and opinions on the availability of PCC information $(p<0.05)$.

Table 2. Table of health-seeking behaviour by site.

\begin{tabular}{cccc}
\hline & $\begin{array}{c}\text { AKUH, } \mathbf{N} \\
\boldsymbol{n} \text { (\%) or Mean } \pm \text { S.D }\end{array}$ & $\begin{array}{c}\text { Maragua } \\
\boldsymbol{n} \text { (\%) or Mean } \pm \text { S.D }\end{array}$ & $\begin{array}{c}\boldsymbol{p} \text {-Value } \\
\text { (Chi-Square/ } \boldsymbol{t} \text {-Test) }\end{array}$ \\
\hline Last time seen by health professional & & & \\
other than for ANC & & & \\
Within 3 months before pregnancy & $43(44.3)$ & $11(11.3)$ & \\
Within 6 months before pregnancy & $16(16.5)$ & $6(6.2)$ & $<0.01$ \\
Within 12 months before pregnancy & $7(7.2)$ & $8(8.2)$ & \\
More than a year before pregnancy & $17(17.5)$ & $38(39.2)$ & \\
Never & $14(14.4)$ & $34(35.1)$ & \\
\hline Purpose of visit to health care professional & & & \\
Regular health check up & $25(25.8)$ & $54(1.0)$ & \\
Sick and needed medical care & $35(36.1)$ & $8(8.2)$ & $<0.01$ \\
To discuss pregnancy plans and preparation & $23(23.7)$ & $34(35.1)$ & \\
Not applicable (i.e., had never seen health & $14(14.4)$ & $16(16.5)$ & \\
professional before) & $34(35.1)$ & $81(83.5)$ & \\
\hline Received PCC: Yes & $63(64.9)$ & & \\
No & & \\
\hline
\end{tabular}


Table 2. Cont.

\begin{tabular}{|c|c|c|c|}
\hline & $\begin{array}{c}\text { AKUH, N } \\
n(\%) \text { or Mean } \pm \text { S.D }\end{array}$ & $\begin{array}{c}\text { Maragua } \\
n(\%) \text { or Mean } \pm \text { S.D }\end{array}$ & $\begin{array}{c}p \text {-Value } \\
\text { (Chi-Square/t-Test) }\end{array}$ \\
\hline \multicolumn{4}{|c|}{$\begin{array}{l}\text { Sought PCC elsewhere other than from } \\
\text { health provider: }\end{array}$} \\
\hline No & $60(61.9)$ & $71(73.2)$ & \multirow{8}{*}{0.19} \\
\hline Yes & $37(38.1)$ & $26(26.8)$ & \\
\hline Family & $16(16.5)$ & $12(12.4)$ & \\
\hline Friend & $16(16.5)$ & $18(18.6)$ & \\
\hline Radio/ Television & $0(0.0)$ & $0(0.0)$ & \\
\hline Social media & $8(8.2)$ & $4(4.1)$ & \\
\hline Traditional healer & $0(0.0)$ & $0(0.0)$ & \\
\hline Other (Internet, google) & $8(8.2)$ & $3(3.1)$ & \\
\hline \multicolumn{4}{|c|}{ Challenges to accessing medical care } \\
\hline Distance & $2(2.1)$ & $2(2.1)$ & \multirow{4}{*}{$<0.01$} \\
\hline Financial & $4(4.1)$ & $28(28.9)$ & \\
\hline Other (time) & $2(2.1)$ & $0(0.0)$ & \\
\hline None & $89(91.8)$ & $67(69.1)$ & \\
\hline \multicolumn{4}{|l|}{ About becoming pregnant } \\
\hline Right time & $79(81.4)$ & $59(60.8)$ & \multirow{3}{*}{$<0.01$} \\
\hline Okay, but not right time & $17(17.5)$ & $29(29.9)$ & \\
\hline Wrong time & $1(1.0)$ & $9(9.3)$ & \\
\hline \multicolumn{4}{|c|}{ Possible to prepare for pregnancy } \\
\hline Yes & $91(93.8)$ & $65(67.0)$ & \multirow{2}{*}{$<0.01$} \\
\hline No & $6(6.2)$ & $32(33.0)$ & \\
\hline \multicolumn{4}{|c|}{ There is enough information about PCC } \\
\hline Yes & $38(39.2)$ & $6(6.2)$ & \multirow{2}{*}{$<0.01$} \\
\hline No & $59(60.8)$ & $91(93.8)$ & \\
\hline
\end{tabular}

Women who received PCC in both sites were $25.8 \%$. There was a significant difference $(p<0.01)$ in the level of PCC in AKUHN, 35.1\% compared to MLFH, 16.5\%.

\subsection{Uptake and Determinants of PCC}

A total of 50 out of the 194 women (25.8\%) received PCC. Of these, 34 women were from AKUH, $\mathrm{N}$ and 16 were from MLFH. In the AKUH, N group, 35.1\% received PCC as opposed to $16.5 \%$ from the MLFH group. There was a significant difference in the level of PCC between the two study sites with a $p$-value of $<0.01$. The odds ratio was found to be $0.3(0.2-0.7)$ which means that the odds of receiving PCC in the MLFH group were 70\% less than in the AKUH, N group. These results have have also been captured in a video summary (Video S1). Figure 1 below demonstrates the level of PCC in the two study sites.

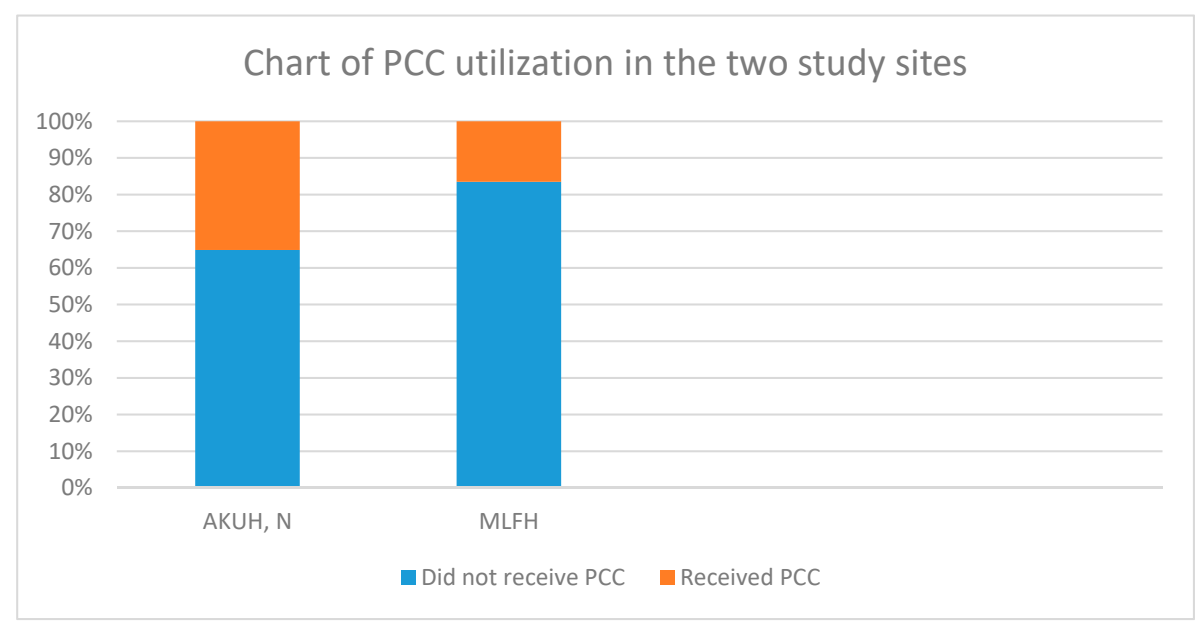

Figure 1. Preconception care (PCC) utilization in the two study sites. 
Table 3 shows the results from the univariate analysis of the association between PCC and other study variables. Age, site, marital status, education, occupation, parity, prior pregnancy outcomes, seeking PCC elsewhere other than from health providers and pregnancy timing were significantly associated with PCC.

Table 3. PCC utilization.

\begin{tabular}{|c|c|c|c|}
\hline Characteristic ( $n=$ Number of Respondents) & PCC Received (\%) & Odds Ratio (95\% Confidence Interval) & $p$-Value \\
\hline Age: $<30$ years & 20/110 (18.1) & & \\
\hline$\geq 30$ years & $30 / 84(35.7)$ & $2.5(1.3-4.8)$ & 0.01 \\
\hline Site: AKUH, N & $34 / 97(35.1)$ & & \\
\hline MLFH & $16 / 97(16.5)$ & $0.3(0.2-0.7)$ & $<0.01$ \\
\hline Marital status: Not Married & $7 / 50(14.0)$ & & \\
\hline Married & $43 / 144(29.9)$ & $2.6(1.1-6.3)$ & 0.03 \\
\hline Education: Below tertiary & 9/76 (11.4) & & \\
\hline Tertiary & $41 / 118(34.7)$ & $4.0(1.8-8.8)$ & $<0.01$ \\
\hline \multicolumn{4}{|l|}{ Occupation: } \\
\hline No formal employment & $16 / 108(14.8)$ & & \\
\hline Formal employment & $34 / 86(39.5)$ & $3.8(1.9-7.5)$ & $<0.01$ \\
\hline Parity: Primigravida & 10/71 (14.1) & & \\
\hline Multigravida & $40 / 123(32.5)$ & $3.0(1.4-6.3)$ & 0.01 \\
\hline \multicolumn{4}{|l|}{ Prior poor pregnancy outcomes } \\
\hline No & $10 / 17(58.8)$ & $3.1(1.6-6.0)$ & $<0.01$ \\
\hline Yes & $30 / 106(28.3)$ & & \\
\hline Miscarriages & $26 / 38(42.1)$ & $2.6(1.2-5.5)$ & 0.01 \\
\hline Preterm birth & $3 / 8(37.5)$ & $1.8(0.4-7.7)$ & 0.44 \\
\hline Stillbirth & $2 / 6(33.3)$ & $1.5(0.3-8.2)$ & 0.67 \\
\hline Birth defects & $1 / 2(50.0)$ & $2.9(0.2-47.5)$ & 0.43 \\
\hline \multicolumn{4}{|l|}{ Preexisting medical conditions: } \\
\hline No & $42 / 164(25.6)$ & & \\
\hline Yes & $8 / 30(26.7)$ & $1.1(0.4-2.3)$ & 0.90 \\
\hline \multicolumn{4}{|l|}{ Sought PCC elsewhere (not health provider): } \\
\hline No & 23/131 (17.6) & & \\
\hline Yes & $27 / 63(42.9)$ & $3.5(1.8-6.9)$ & $<0.01$ \\
\hline \multicolumn{4}{|l|}{ Challenges to accessing medical care: } \\
\hline No & $40 / 156(25.6)$ & & \\
\hline Yes & $10 / 38(26.3)$ & $1.0(0.5-2.3)$ & 0.94 \\
\hline \multicolumn{4}{|l|}{ About becoming pregnant } \\
\hline Not right time & $8 / 56(14.3)$ & & \\
\hline Right time & $42 / 138(30.4)$ & $2.6(1.1-6.0)$ & 0.02 \\
\hline \multicolumn{4}{|l|}{ There is enough information about PCC: } \\
\hline No & $34 / 150(22.7)$ & & \\
\hline Yes & $16 / 44(36.4)$ & $2.0(0.9-4.0)$ & 0.07 \\
\hline
\end{tabular}

Univariate analysis revealed a strong association between PCC and age, site, marital status, education level, occupation, parity, prior poor pregnancy outcomes, seeking PCC elsewhere and pregnancy timing. These variables were entered into SPSS version 22 and subjected to multivariate logistic regression with the uptake of PCC being the dependent variable and the others (age, site, marital status, education level, occupation, parity, prior poor pregnancy outcomes, seeking PCC elsewhere and pregnancy timing) as independent variables, in order to control for the influence of each of the independent variables. The independent variables were entered together in SPSS and not one by one. This analysis generated adjusted odds ratios which were presented with a $95 \%$ confidence interval as outlined in Table 4 below. However, because of the low sample size the confidence intervals were wide and no significant difference below the 0.05 level were found, but trends towards statistical significance were observed for education and prior poor pregnancy outcomes. 
Table 4. Multivariate logistic regression.

\begin{tabular}{ccc}
\hline Variables & Adjusted Odds Ratio (95\% Confidence Interval) & $p$-Value \\
\hline Site & $1.32(0.479-3.612)$ & 0.60 \\
Age & $1.18(0.552-2.511)$ & 0.67 \\
Marital status & $1.58(0.587-4.227)$ & 0.37 \\
Education & $3.08(0.955-9.940)$ & 0.06 \\
Occupation & $2.20(0.951-5.083)$ & 0.07 \\
Parity & $1.68(0.607-4.652)$ & 0.32 \\
Prior poor pregnancy outcomes & $2.39(0.978-5.861)$ & 0.06 \\
\hline
\end{tabular}

\section{Discussion}

In this study, only $25.8 \%$ of the participants received PCC while $96 \%$ of pregnant women in Kenya are attending ANC [5]. This points to different factors affecting the utilization of different maternal health services in Kenya. From this study, many women felt that there was not enough information about PCC which could partly explain its underutilization locally. However, our study revealed that lack of information on PCC was not a significant determinant of PCC utilization pointing to a role that other factors play. Factors such as age, marital status, site of health facilities, parity and prior poor pregnancy outcomes were shown to have potential effects on PCC utilization. Studies that have looked at the determinants of other maternal health services in Kenya [15-17] and determinants of PCC utilization in other parts of the world $[8,9,18]$ demonstrated the role played by the aforementioned factors. The older, married, parous women as well as those who reside in urban areas and those with a history of prior poor pregnancy outcome, are more likely to use PCC as well as other maternal health services which agrees with what was demonstrated in this study. Our findings align with the low uptake of PCC in Africa and globally in comparison to other maternal health services [7-11,18], underlining the need to create awareness and demand for PCC both locally and globally.

More women in the urban health facility received PCC compared to the rural health facility which could be due to differences in age, marital status, education, occupation and parity between the sites as shown by earlier data from Kenya. Several studies in Kenya showed that older maternal age, higher education level, being employed and being married-especially marriage to an educated and employed partner-were significantly associated with the increased use of maternal health services, while parity had mixed effects [15-17]. The mixed effects of parity could arise from prior use of maternal services that could lead to feeling well versed hence no further need for them or having insight into the importance of the services hence encouraging more use.

The mean age at the urban facility was higher than at the rural facility. This is in keeping with the trend of higher maternal age in urban areas compared with the rural areas as women pursue education and career advancement and postpone marriage [12]. In support of this, there were more women with tertiary education and formal employment in the urban health facility. These work hand in hand to increase both awareness and utilization through increasing financial accessibility. Additionally, more women in the urban health facility believed there was enough PCC information and fewer had financial challenges. The proportion of married women in the sample differed at the urban and rural sites-with more married women in the urban sample. It is, therefore, possible that the older, more educated hence more informed, employed and married women in urban settings were advantaged and hence likely to receive PCC compared to their rural counterparts. This can also be supported by the higher rates of routine PCC in the urban health facility.

Another reason for the difference in PCC could arise from the higher rates of the urban women who had their pregnancies planned, which may imply more time, thought and deliberation put into the process, and hence the likelihood of seeking help to optimize pregnancy outcomes. Family planning is part and parcel of PCC as it may help to optimize maternal health prior to pregnancy, for example in the setting of chronic and infectious diseases. This was supported by findings from other studies in the literature of pregnancy planning as a promoter of PCC and vice versa $[9,18]$. This is further 
supported by the KDHS 2014 report that showed a higher CPR and lower unmet contraceptive need in urban compared to rural areas [12]. The PCC difference could also be explained by the higher number of women in the urban setting who believed in the possibility of women preparing for pregnancy, which may translate to a higher self-efficacy, and consequently, more receptivity to PCC services.

In line with what would be expected, there were more women in the urban setting with poor prior pregnancy outcomes despite having a higher level of PCC. A possible explanation is that the higher number of women with poor prior pregnancy outcomes in the urban setting served as the driving force for more PCC utilization in pursuit of better outcomes in the future. Overall, PCC provides an opportunity to optimize a woman's health in order to provide a safe fetal environment and consequently offer multigenerational benefits. It also results in improved health of the children through prevention of infection transmission such as HIV/AIDS (human immunodeficiency virus and acquired immune deficiency syndrome) and lowering the risk of some forms of childhood cancers, obesity, type 2 diabetes mellitus and cardiovascular diseases in later life [1,19]. Alternatively, AKUH, $\mathrm{N}$ being a tertiary and referral hospital, could be receiving more women referred there due to bad prior outcomes compared to MLFH, a public level four hospital. Another explanation could be that some women in MLFH with prior bad outcomes choose to seek help elsewhere instead of hospitals or not at all, due to challenges in accessing health care in the rural areas as found in this study.

The level of PCC revealed in this study is higher in comparison to that found in three separate Nigerian studies, two in urban settings [8,10] and one in a semi-urban setting [11]. A possible explanation for this could lie in the differences in the socio-demographics of the study participants as explained above. The participants' characteristics in the Southeastern Nigeria (urban) study were comparable to the participants in $\mathrm{AKUH}, \mathrm{N}$, a similar study setting, with a mean age of 30 years in both and study population of pregnant women seeking ANC. However, there were differences in the proportion of married women, those with at least a tertiary education, and primigravid in Southeastern Nigeria and AKUH, N [8]. Being married has been associated with increased utilization of maternal health services in different studies as previously discussed $[15,17,20]$. All women in the Southeastern Nigeria study were married but despite that, there was a lower level of PCC in comparison to AKUH, $\mathrm{N}$ women. This may point to an interplay of other factors such as socio-demographic characteristics of the partners and parity (more were multiparous in the Nigerian study) which was associated with less use of PCC from feeling well versed. More women in AKUH, N than Southeastern Nigeria sought PCC as routine, and this could be because more women in AKUH, $\mathrm{N}$ had at least a tertiary education which affects awareness levels. In both centers, however, this was the commonest reason for receiving PCC [8], which offers hope for increased PCC utilization with public education.

There were differences in the Northern Nigeria study (semi-urban) [11] compared to MLFH. The former studied women who had delivered within 24 months of the survey while in MLFH pregnant women attending ANC were studied. Therefore, there is a possibility of recall bias in the Northern Nigeria study since women had to recollect events that had happened over 24 months prior to data collection. There were differences in the mean age, the unemployed and those with at least a tertiary education in Northern Nigeria study and MLFH. All these factors showed significant associations with not only PCC utilization but also with other forms of maternal health services as discussed above and provide a possible explanation for the difference observed in the two studies. Another explanation for this could lie in the regional and country-wise differences in public health-seeking behaviors with Northern Nigeria having low demand for and utilization of maternal health services [21].

\subsection{Strengths}

This was a pilot study that compared the uptake and factors affecting PCC in both urban and rural settings, as well as in a private and a public hospital in Kenya. It is one of the very few studies conducted in Kenya in the area of PCC, which is an area that offers clear health benefits and is highly underutilized. This study may contribute to the bulk of PCC knowledge and awareness in order to inform policies and practices. 


\subsection{Weaknesses}

The limitations of this study include the sample size that was not powered to allow firm conclusions to be drawn and the inability to analyze the role of some potentially confounding factors. There could also be a recall and reporting bias on the question of whether or not the participants received PCC from a health provider, given the variations in gestational age at enrollment. Further, these findings may not apply to urban women with different socio-demographic characteristics like those from the slums hence, a separate study in low resource urban areas may be helpful.

\section{Conclusions}

This is a first-of-its-kind pilot study into differences in PCC utilization in an urban and a rural health facility in Kenya. The main finding of this study was that the level of PCC in this setting, albeit low, is comparable to the global levels. This finding is interesting as both the WHO and the Ministry of Health in Kenya recognize the importance of PCC in policies aimed at reducing child mortality and improving maternal health $[1,4,22]$. In addition, there was a significant difference in the level of PCC utilization between the two study sites-lower in the rural rather than urban settings. This difference may be attributable to variance in the socio-demographic characteristics between the two study populations. Other factors may be at play here, such as differences in rural and urban demographics, infrastructure and access to resources, the differential impact of health policies and systems in urban and rural settings — this study did not look at these.

The small sample size of this study limits the strength of the conclusions about the determinants of PCC use in both settings. However, the findings are interesting and indicative. Further research is this field is therefore necessary in order to help inform strategies towards increasing PCC awareness and utilization in Kenya.

As a beginning of preconception care research in Kenya, this study can be considered as a pilot study and further research on the field is highly recommended.

Supplementary Materials: The following are available online at http://www.mdpi.com/1660-4601/17/20/7430/s1, Video S1: Uptake of preconception care in an urban and a rural health facility in Kenya.

Author Contributions: Conceptualization of the study was done by J.O. with the help of M.M., M.T. and D.K. M.T., M.M. and D.K. contributed to the study methodology and software and played the supervision role. J.O. carried out the validation, investigation and formal analysis of data. All the authors contributed to data curation. J.O. did the original draft preparation. All the authors contributed in reviewing and editing of the manuscript as well as visualization. J.O. did the project administration. Funding acquisition was through J.O. courtesy of the AKUH, N postgraduate medical education program. All authors have read and agreed to the published version of the manuscript.

Funding: The funding for this study was provided by the AKUH, N postgraduate medical education program, which funds all of their students' research work.

Conflicts of Interest: The authors declare no conflict of interest.

\section{References}

1. World Health Organization. Meeting to Develop a Global Consensus on Preconception Care to Reduce Maternal and Childhood Mortality and Morbidity: World Health Organization Headquarters, Geneva, 6-7 February 2012; Meeting Report, 2013; World Health Organization: Geneva, Switzerland, 2013.

2. Say, L.; Chou, D.; Gemmill, A.; Tunçalp, Ö.; Moller, A.-B.; Daniels, J.; Gülmezoglu, A.M.; Temmerman, M.; Alkema, L. Global causes of maternal death: A WHO systematic analysis. Lancet Glob Health 2014, 2, e323-e333. [CrossRef]

3. Jack, B.W.; Atrash, H.; Coonrod, D.V.; Moos, M.-K.; O’Donnell, J.; Johnson, K. The clinical content of preconception care: An overview and preparation of this supplement. Am. J. Obstet. Gynecol. 2008, 199, S266-S279. [CrossRef] [PubMed]

4. Ministry of Public Health and Sanitation. National Reproductive Health Strategy 2009-2015; Ministry of Public Health and Sanitation: Nairobi, Kenya, 2009. 
5. Demographic, K. Health Survey 2014: Key Indicators; Kenya National Bureau of Statistics (KNBS) and ICF Macro: Nairobi, Kenya, 2014.

6. Defo, B.K. The importance for the MDG4 and MDG5 of addressing reproductive health issues during the second decade of life: Review and analysis from times series data of 51 African countries. Afr. J. Reprod. Health 2011, 15, 9-30. [PubMed]

7. Frey, K.A.; Files, J.A. Preconception healthcare: What women know and believe. Matern. Child Health J. 2006, 10, S73-S77. [CrossRef] [PubMed]

8. Ezegwui, H.U.; Dim, C.; Dim, N.; Ikeme, A.C. Preconception care in South Eastern Nigeria. J. Obstet. Gynaecol. 2008, 28, 765-768. [CrossRef] [PubMed]

9. Stephenson, J.; Patel, D.; Barrett, G.; Howden, B.; Copas, A.; Ojukwu, O.; Pandya, P.; Shawe, J. How do women prepare for pregnancy? Preconception experiences of women attending antenatal services and views of health professionals. PLoS ONE 2014, 9, e103085. [CrossRef] [PubMed]

10. Ekem, N.N.; Lawani, L.O.; Onoh, R.C.; Iyoke, C.A.; Ajah, L.O.; Onwe, E.O.; Onyebuchi, A.K.; Okafor, L.C. Utilisation of preconception care services and determinants of poor uptake among a cohort of women in Abakaliki Southeast Nigeria. J. Obstet. Gynaecol. 2018, 38, 739-744. [CrossRef] [PubMed]

11. Idris, S.H.; Sambo, M.N.; Ibrahim, M.S. Barriers to utilisation of maternal health services in a semi-urban community in northern Nigeria: The clients' perspective. Niger. Med. J. J. Niger. Med. Assoc. 2013, 54, 27-32. [CrossRef] [PubMed]

12. Statistics, K.N.B. Kenya Demographic and Health Survey 2014; Kenya National Bureau of Statistics: Nairobi, Kenya, 2015.

13. Nairobi City County. The Project on Integrated Urban Development Master Plan for the City of Nairobi in the Republic of Kenya; Nairobi City County Nairobi: Nairobi, Kenya, 2014.

14. Ndegwa, E. Murang'a County Council Integrated Regional Development Plan (2013-2017); Kenya Open Data: Nairobi, Kenya, 2013.

15. Kawakatsu, Y.; Sugishita, T.; Oruenjo, K.; Wakhule, S.; Kibosia, K.; Were, E.; Honda, S. Determinants of health facility utilization for childbirth in rural western Kenya: Cross-sectional study. BMC Pregnancy Childbirth 2014, 14, 265. [CrossRef] [PubMed]

16. Jalang'O, R.; Thuita, F.; Barasa, S.O.; Njoroge, P. Determinants of contraceptive use among postpartum women in a county hospital in rural KENYA. BMC Public Health 2017, 17, 604. [CrossRef] [PubMed]

17. Banke-Thomas, A.; Banke-Thomas, O.; Kivuvani, M.; Ameh, C.A. Maternal health services utilisation by Kenyan adolescent mothers: Analysis of the Demographic Health Survey 2014. Sex. Reprod. Healthc. 2017, 12, 37-46. [PubMed]

18. Ayalew, Y.; Mulat, A.; Dile, M.; Simegn, A. Women's knowledge and associated factors in preconception care in adet, west gojjam, northwest Ethiopia: A community based cross sectional study. Reprod. Health 2017, 14, 15. [CrossRef] [PubMed]

19. World Health Organization. Preconception Care: Maximizing the Gains for Maternal and Child Health; World Health Organization: Geneva, Switzerland, 2013.

20. Okonofua, F.; Ntoimo, L.; Ogungbangbe, J.; Anjorin, S.; Imongan, W.; Yaya, S. Predictors of women's utilization of primary health care for skilled pregnancy care in rural Nigeria. BMC Pregnancy Childbirth 2018, 18, 106. [CrossRef] [PubMed]

21. Sinai, I.; Anyanti, J.; Khan, M.; Daroda, R.; Oguntunde, O. Demand for Women's Health Services in Northern Nigeria: A Review of the Literature. Afr. J. Reprod. Health 2017, 21, 96-108. [CrossRef] [PubMed]

22. WHO. Global Action Plan for the Prevention and Control of Noncommunicable Diseases 2013-2020; WHO Press: Geneva, Switzerland, 2013.

(C) 2020 by the authors. Licensee MDPI, Basel, Switzerland. This article is an open access article distributed under the terms and conditions of the Creative Commons Attribution (CC BY) license (http://creativecommons.org/licenses/by/4.0/). 